\title{
Review: The Impact of Covid-19 and Possible Mechanisms on Prevention of Suicidal Ideations
}

\author{
Cho Cho Zaw Raheema ${ }^{1 *}$, Myat Min Mohd Omar ${ }^{2}$
}

${ }^{1}$ Kulliyyah of Nursing, IIUM Kuantan Campus, Pahang, Malaysia

${ }^{2}$ Kulliyyah of Allied Health Sciences, IIUM Kuantan Campus, Pahang, Malaysia

DOI: $10.36347 /$ sjams.2020.v08i11.009

| Received: 29.10.2020 | Accepted: 07.11.2020 | Published: 11.11.2020

*Corresponding author: Cho Cho Zaw Raheema

Abstract

Covid-19 known as the '2019 Novel Coronavirus (2019-nCoV) Pneumonia' is believed to spread from Wuhan, China, then aroused the global attention due to its fast spread nature throughout the World. In March 2020, World Health Organization (WHO) declared Covid-19 as a global pandemic. Covid-19 causes a tremendous impact to people throughout the world by affecting their physical, mental, social, and financial aspects of their life. Many studies have been pointed out the relationship between stress and suicide, and it is noted that Covid-19 also relates psychological problems among people by making them anxious, stress and worries. Thus, this study is intended to explore the impact of Covid-19, and its relationship with suicidal ideation, and the possible mechanisms to prevent it. The qualitative study by literature review method was used as a methodology. The findings were categorized into two major themes: (i) the impact of Covid-19 and its relationship with suicidal ideation, in which three sub-themes were identified as economic, social, and psychological; and (ii) the possible mechanisms for prevention of suicidal ideation, in which four sub-themes were identified as 'guidelines on suicide prevention and emergency crisis', 'raising awareness regards to suicidal ideation and attempts', 'online mental health services for suicide prevention' and 'limitation of watching news and social media'. The discussions were made based on the identified information such as the impact of Covid19, mental health issues and suicidal ideation, preventive measures against suicide including health education, community awareness, online mental health services, government guidelines in preventing suicide, and the national support. The need for further research by using different methodologies was recommended. It is hoped that this paper serves as a source of information for public awareness on suicidal ideation and possible mechanisms to prevent it.

Keywords: Impact of Covid-19, suicidal ideation and attempt, awareness and preventive mechanisms, online mental health services, government guidelines.

Copyright $\odot 2020$ The Author(s): This is an open-access article distributed under the terms of the Creative Commons Attribution 4.0 International License (CC BY-NC 4.0) which permits unrestricted use, distribution, and reproduction in any medium for non-commercial use provided the original author and source are credited.

\section{INTRODUCTION}

Covid-19 formally known as the '2019 Novel Coronavirus (2019-nCoV) Pneumonia', is believed to spread beginning from early December 2019 from a wet market in Wuhan, China then aroused the global attention due to its rapid spread throughout the world starting from late January 2020 [1]. In March 2020, World Health Organization (WHO) declared Covid-19 as a global pandemic due to its alarmingly rapid spread and troublesome consequences [2]. In Malaysia, Covid19 was first detected on 24 January 2020. It is derived from a newly discovered strain of coronavirus, causing respiratory infections, and discovered after identifying the unknown outbreak of pneumonia in China [3]. This virus has been identified as severe acute respiratory syndrome coronavirus 2 (SARS-CoV-2) by Chinese Center for Disease Control and Prevention (CCDC) which can lead to severe and fatal respiratory disease that can end up in intensive care [4].

Covid-19 can be transmitted through direct, indirect, or close contact with infected people, and a person who infected with it could be symptomatic or asymptomatic. The mode of transmission is mostly airborne and contact or droplets. It is highly contagious and able to spread between person to person through close contact (within 6 feet), respiratory droplets from an infected person through coughing and sneezing, or touching the mouth, nose, or eyes after contact with a contaminated surface or object [5].

In regard to the characteristic of Covid-19, a study conducted among the 138 hospitalized patients revealed that the common symptoms of it as fever (98.6\%), fatigue $(69.6 \%)$, and dry cough (59.4\%), lymphopenia (reduced lymphocyte count) (70.3\%), 
prolonged prothrombin time (58\%), and elevated lactate dehydrogenase (39.9\%). Moreover, Chest computed tomographic scans revealed the patchy shadows or ground glass opacity in the lungs of all patients. Out of all patients, $26.1 \%$ were transferred to the intensive care unit (ICU) due to complications such as acute respiratory distress syndrome, arrhythmia, and shock [6]. The symptoms of Covid-19 virus are varied depends on the strain of it which might spread differently in various parts of the world or even within the same country depends on the specific cluster.

In addition to the physical symptoms, Covid19 causes mental, social, and psychological impact to people throughout the world. It is noted that Covid-19 causes a tremendous amount of psychological stress and pressure. Numerous studies have been conducted on the relationship between psychological stress and suicide rates even years before the outbreak of Covid-19 virus. Several factors contributed to the causes of suicide such as physical, mental, social, and economical. The suicide rates tend to be higher among people who have been experiencing physical and mental illness, depression, financial crisis, feelings of hopelessness, taken advantage of, and trapped in a situation perceived as negative, not being accepted by family, and friends, the loss of their loved ones, jobs or properties, who are the victims of any forms of physical, mental, psychological, sexual abuse, people with alcohol and drug use [7].

A study conducted in China identified that about one-third of the participants were having psychological distress [8]. The immense amount of stress is related with Covid-19 and the suicidal ideations and attempts to suicide included as one of the emergency crises. Thus, the psychological impact of Covid-19 should never be neglected, and mental health services and guidelines are needed for this critical period in every countries of the world affected by this virus.

Moreover, it is not uncommon to note the tragic news of suicide during this time of Covid-19 outbreak especially among the immigrant workers from the social media. These incidents can lead us to a curiosity of exploring about suicide during Covid-19, study the possible ways of preventing the suicidal ideations and help reduce the suicide rates among the public.

Thus, this study aims to explore the nature of Covid-19 and its impact on physical, mental, social, and economical aspects. This study is also intended to identify the relationship between the psychological impact of Covid-19 and suicidal ideation. In addition, it is intended to examine the possible mechanisms to prevent the suicidal ideations which will help reduce the suicide rates.

\section{Methodology}

The analytical literature review was used for this study as a methodology. The literature related with Covid-19 were identified through google, google scholar, PubMed and other online sources such as the website as Lancet Psychiatry, and JAMA Psychiatry. The impact of Covid-19 on suicidal ideations and rates were examined by reviewing the online and offline available literature. The articles published between January 2020 January to June 2020 were searched focused on the Covid 19 and its impact. The key word such as 'Covid-19', 'Covid-19 and suicidal ideations', 'Covid-19 and suicide rates' were typed and searched through open access journals. Based on the findings of the literature search related with Covid-19, the discussions were made under each theme which were categorized based on the similar concept and topics.

\section{IMPACT OF COVID-19}

Covid-19 has affected either directly or indirectly to everyone in the world leaving no lives untouched. According to United Nations [9], there were about 272 million international migrants including refugees and asylum-seekers at mid-2019 in US. It can increase the burden of vulnerable migrants' population such as people working illegal, fleeing from their countries, displaced internally inside their own country, or refugees across international border. The situation make it worsen and lead them left struggling in the area of health crisis, socioeconomic crisis, and protection crisis due to the result of their crowded conditions, reduced access to health services, and food insecurity.

\section{ECONOMIC IMPACT OF COVID-19}

Many studies have identified the relationship between public health such as mortality and morbidity rates compared to economic welfare and growth. Infectious diseases outbreak can influence the economy of the country. Covid-19 pandemic outbreak has disturbed the economy of China and is spreading worldwide [10].

It is noted that the suicide rate is usually higher during economic recessions compared to the prosperous time. The increased in suicide rate is linked with the rise of unemployment and downsizing of the economy. Due to the pandemic, the cancelled events, the closed businesses have faced difficulty and employees are reduced or lay off. In addition to that, some parents have to take time off work to take care of the children during periods of school closure [11].

In Malaysia, Covid-19 was first reported on 25 January and the number raised up to 428 by mid-March. On 18 March 2020, the non-essential business and services were shut down, interstate travel was restricted and all the events such as Public sporting, religious, and social gatherings were cancelled due to the Movement Control Order (MCO) issued by the authorities. The Malaysian economy was intensely affected due to the 
impacts of the virus abroad, as well as domestically generated movement control order [12]. Thus, the economic policy responses from the government such as safeguarding employment and livelihoods as primary measure and helping the businesses as secondary measure to counter the damaging economic effect of the country was suggested. However, for the second wave of Covid-19 spread, the government is facing the challenges of issuing movement order due to the high risk of economic losses in the country which could lead many citizens suffer including business owners, staffs, and ordinary people.

Moreover, Kawohl and Nordt [13] described that the rate of distressed people who seek the help of mental health services during Covid-19 pandemic are expected to increase. Thus, they suggested for providing hotlines and psychiatric services to respond appropriately for the vulnerable group in the society.

\section{SOCIAL IMPACT OF COVID-19}

Social isolation and loneliness have been linked to physical and mental well-being of humans. Social connections play an important role in suicide prevention. People with lack of social connections and loneliness usually tend to have higher suicidal ideation and increased risk of suicide [14]. One study conducted in US pointed out that attending religious services weekly have 5-fold lower suicide rate compared with those who do not attend [15]. During Covid-19 outbreak, the impact of closing religious activities such as attending mosque, churches, temples, and other centers would contribute to increase suicide rate.

Thus, social connections and communications through various available channel are suggested during periods of social distancing to prevent feelings of isolations and loneliness. These includes the use of phone, FaceTime, Skype and other forms of social media to sustain a sense of connection with others [13]. Stanley et al., [16] also pointed out the importance of social engagement, maintaining social bonds, and seeking interpersonal support while keeping safe physical distance regardless of the movement limitations.

\section{PSYCHOLOGICAL IMPACT}

In addition to the physical sufferings, it is undeniable that patient with Covid-19 usually develop psychological problems. The outcomes of isolation and quarantine cause to increase suicide ideation and behaviors among the high-risk population [17]. This outbreak is emotionally challenging for people especially those with underlying depression and other mental health issues.

Moreover, the limited knowledge of the Covid19 and the overwhelming news may lead to anxiety and fear in the public [18]. Moreover, the condition make it worse when the routine mental health care services are hindered by the barriers such as screening requirement for Covid-19 at the entry points, not being allowed to enter without appointment, cancelled appointments related with child care during school closure, and mental health services not being prioritized due to overwhelmed health care settings, and reduced mental health care to patients with suicidal ideation or survivors of suicide attempts [11]. As a result, they may experience psychological problems such as loneliness, denial, anxiety, depression, insomnia, and despair, which may increase the risk of aggression and suicide [19].

In addition to the public, it is no exceptions to Health professionals who are working as frontliners for Covid-19 infected cases. They have experienced the psychological pressure due to the fear of being infected and contagion of disease, as well as facing the public enquiry [20]. Moreover, aw study was conducted in China among 1257 health care workers from 34 hospitals who are assigned in fever clinic or wards for patients with Covid-19. A considerable amount of them revealed that they have experienced symptoms of depression, anxiety, insomnia, and distress especially women nurses and front-line health care workers in Wuhan involved in direct care and treatment of Covid19 patients. These findings indicate that the health care workers have a high chance of acquiring undesirable mental health outcomes and the need for psychological support or interventions to them [21].

Many studies highlighted the increase suicide rates among the health care professionals, and strategies at the workplace should prevent their suicidal ideation [22]. The strategic planning from the part of government is needed to support the health care workers who are the frontline warrior to fight against Covid-19.

\section{POSSIBLE MECHANISMS FOR PREVENTION OF SUICIDAL IDEATION}

The control and prevention of Covid-19 is not adequate with an effort from the individual organization alone, and it goes up to the national and global level. Numerous challenges could be faced in controlling the virus, and prevention of psychological and other negative impacts. However, it is needed to find out the opportunities and identify the possible mechanisms for suicide prevention.

\section{GUIDELINES ON SUICIDE PREVENTION AND EMERGENCY CRISIS}

In Malaysia, the WHO Country Office has been working closely with the Ministry of Health by setting guidelines and strengthening of the system to deal with the outbreak [23], and described that suicide in a population is accompanied by more than 20 suicide attempts. 
Thus, the suicidal ideation should be prevented by using different strategies. The policies and standard procedures should be initiated at the national and ministry level of the country, after collaboration among different professionals and disciplines. It is worthwhile to develop guidelines to increase awareness of the suicidal ideations and prevent suicide attempts.

In China, in regard to the interventions for emergency psychological crisis, expert teams from the various mental health associations and organizations were established to develop guidelines and public health educational resources and online mental health services under the guidance of the National Health Commission of China. For providing on-site services, mental health experts and professionals are assigned at the designated isolation hospitals. The challenges are still at large due to the rapid transmission of the Covid-19 [24].

In Malaysia, staff support during Covid-19 Mental Health and Psychosocial support (MHPSS) was initiated and all relief providers involved in the Covid19 response are equipped with basic psychosocial support skills. They were suggested to use the guidelines in different languages which were developed as the results of discussions between the experts, emergency responders and survivors of Covid-19 from 24 countries [25].

Moreover, research has been conducted to provide effective interventions for psychological crisis not only for the public, but also for the frontliners. In University Sabah Malaysia (USM), Brief intervention for Mental Health and Psychosocial support service was introduced by using locally adapted Ultra Brief Psychological Interventions (UBPM) in dealing with Covid-19 Pandemic to be performed by health care professionals [26]. It takes less than 15 minutes and incorporate a variety of evidence-based psychological interventions, and collaborative skills. Regarding preventing health care workers stress and burnout, the arrangement for providing adequate supplies of PPE and adequate staff numbers, the fair distribution of their workload, training, and psychological support to them are necessary.

\section{RAISING AWARENESS REGARDS SUICIDAL IDEATION AND ATTEMPTS}

During Covid-19 outbreak, while social distancing is the requirement for prevention of it, the connection among people still need to be maintained. Reger et al., [11] mentioned that "Despite its name, social distancing requires physical space between people, not social distance", and they suggested the need to explore social media solutions to facilitate these goals. There are a variety of ways to communicate each other through phone, text messages, and video calls. The awareness of the public to make a regular call to their friend or family member who are among the highrisk groups is also important.
According to estimation of WHO, there are approximately 1 million annual death rates due to the suicide. Smith, et al., listed out many ways to help save a life by observing suicide warning signs such as when a person is talking about suicide (e.g. "I'd be better off dead."), seeking out lethal means (seeking the objects that could be used in a suicide attempt), preoccupation with death (writing poems or stories about death), no hope for the future (feelings "There's no way out"), self-hatred ("everyone would be better off without me"). They also suggested to be alerted for other signs such as when a person is getting affairs in order (giving away possessions, making arrangements for family members), saying goodbye (unusual visits/calls to family and friends), withdrawing from others (desire to be left alone), self-destructive behavior (increased alcohol or drug use, taking unnecessary risks) and a sudden sense of calm observed after being extremely depressed (which could mean the decision to make suicide has been made) [27].

The support from family and friends and their awareness about suicide ideation and ways to help them out are important. The suicide prevention tips included allowing to express their feelings, listening with nonjudgmental approach, offering help and assistance, removing dangerous items around them, encouraging them to take medications regularly if being prescribed, and seek professional help if needed. The use of relaxation techniques, maintaining healthy lifestyle with regular exercise, enough sleep and balanced diet, behavioral and cognitive therapy are also required.

\section{ONLINE MENTAL HEALTH SERVICES FOR SUICIDE PREVENTION}

The government and health ministry should arrange for having increased access to mental health care services. Patients with mental health issues might encounter crisis such as cancelation of appointments, sending back homes due to the screening and prevention procedures for Covid-19 which lead them to have reduce access to health care. Thus, Reger [11] suggested the arrangement of alternative treatment settings (eg, a private sector) rather than sending patients back home.

Furthermore, online mental health services or distance-based suicide prevention are also suggested. The public have been dealing with mental health issues such as stress, worries, and anxiety due to the rapid emergence of Covid-19 confirmed cases and deaths. Moreover, the medical staff who have been treating, and caring Covid-19 patients have experienced the intense amount of pressure due to their increased workload, the fear of contracting disease to themselves and their loved ones. Furthermore, the public stigma against the health care workers added to their burden and stress. Thus, online mental health services should be provided not only to the public but also to the health care workers and other frontliners. 
Reger [11] mentioned the benefits of suicide prevention interventions such as brief contact interventions (telephone-based outreach) and the Caring Letters intervention (in which letters are sent through the mail) in reducing suicide rates in US. They highlighted the importance of Follow-up contact for individuals with positive Covid-19 and suicide risk factors. The use of tele-mental health, as part of telehealth is recommended. However, the infrastructure such as computer with high-speed internet access and potential legislative protections must be addressed.

In China, as of February 8, 2020, there are 72 online mental health surveys related with Covid-19 which target different population groups such as medical staff, students, general population, mixed population, and Covid-19 patients. Moreover, 29 books associated with Covid-19 have been published and 11 $(37.9 \%)$ of which are on mental health. One multicentre survey conducted in 1563 medical staff revealed the prevalence of depression $50.7 \%$, anxiety $44.7 \%$, insomnia $36.1 \%$, stress-related symptoms $73.4 \%$. These findings are necessary for health authorities in allocating resources and developing appropriate treatments for medical staff with mental health issues. In addition, online mental health education and psychological counselling services were widely conducted to facilitate public emergency interventions [28].

In the US, Medicare allocates budget for telehealth to be adopted rapidly. However, the importance of access to technology and digital literacy were highlighted since $75 \%$ of people were not aware of telehealth option before the pandemic [29]. Thus, the need for developing internet availability and providing affordable and high-speed internet access are suggested to improve the usage of telehealth programs.

\section{LIMITATION OF WATCHING NEWS AND SOCIAL MEDIA}

The widespread media coverage of a collective crisis during Covid-19 may amplify distress since it made it easier for them to get sucked into press conference and obsessively check for updates. While media reporting is the essential channel for the public to communicate critical information and necessary precautions to keep the public well-informed, the psychological stress emerged due to the media include as one of the related threats. The repeated media exposure regards to the outbreak can lead to higher level of stress, and anxiety [30] which in-turn link with the suicidal ideations. Thus, another suggestion to reduce the psychological impact is to limit news and social media which make them worries and by not following the information at all time.

It is suggested that media reports on this topic should follow the media guidelines in order to prevent the suicide contagion [11]. For this, Dolgin [31] also recommended to spend a few times a day only to check for updates and stick to reliable news outlets since rumors can spread fast and lead to the panic state. Other suggestions included are to change the expectations by not setting unrealistic goals, and doing what you can, doing something different by planning to have variety of activities within the limitations instead of sucking in monotonous and boring atmosphere.

\section{CONCLUSIONS AND RECOMMENDATIONS}

This study highlighted the physical, social, economic, and psychological impact of Covid-19 and possible mechanisms to prevent the suicidal ideations and dealing with psychological issues. As per discussions before, the occurrence and spread of the Covid-19 have caused immense amount of stress and psychological problems among the global populations. People especially with underground health problems and mental health issues have tremendous pressure compared to the normal times which lead them to have increased suicidal ideations and suicide attempts.

However, there are also still opportunities to prevent suicidal ideations and suicide. Maintaining effective communication skills, providing health education, increasing community awareness about suicide will help to improve the condition and response toward the crisis. Moreover, National and governmental level should arrange for providing the finical support and assistance to those in need, the alternative arrangement for job opportunities, establishment of support group, and the guidelines for psychological emergency response, and strategies to get reduced access to instruments used for suicide.

Moreover, the government policy should support for developing online mental health services to get increased access to mental health care. Online mental health services have been constructed in different countries across the world, there are still challenges in providing it effectively. It might be a challenge for some population who may have limited access to the services due to restricted or inability to use technology. Thus, the management and coordination effort, the government assistance to social and financial support, the adequacy of health care members is necessary.

Furthermore, being a newly started pandemic, some of the effect of Covid-19 are yet to be coming. It is worthwhile to conduct research in various sector regards to Covid-19, the impact, and prevention strategies of it. It is suggested to use different methodologies to explore the relationship between Covid-19 and the psychological responses and develop appropriate interventions in dealing with the situations. more studies focusing on the effect of media and the psychological stress should be further explored, even 
though this study pointed out the general understanding of the effect of media and Covid-19.

In addition, more research with different approaches and methodologies such as quantitative and qualitative studies are suggested to conduct. The detailed prevention strategies and recommendations should be established based on the findings of the study. The suggestions from the participants, researchers, and public health officials should be considered in developing guidelines and standards of the nations.

\section{REFERENCES}

1. Lu H, Stratton CW, and Tang YW. Outbreak of Pneumonia of Unknown Etiology in Wuhan, China: The Mystery and the Miracle. Journal of medical virology.

2020. https://doi.org/10.1002/jmv.25678

2. WHO (World Health Organization) Regional Office for Europe. 2019-nCoV Outbreak is an Emergency of International Concern. 2020; Dated 31.1.2020. retrieved on 20.10.20 from https://www.euro.who.int/en/health-topics/healthemergencies/coronavirus-Covid-

19/news/news/2020/3/who-announces-Covid-19outbreak-a-pandemic

3. WHO (World Health Organization). Coronavirus (COVID-19) in Malaysia. Last updated: 08 September 2020. Retrieved 20.10.20 from https://www.who.int/malaysia/emergencies/corona virus-disease-(Covid-19)-in-malaysia

4. Huang C, Wang Y, Li X, Ren L, Zhao J, Hu Y. Clinical Features of Patients Infected with 2019 Novel Coronavirus in Wuhan, China. Lancet (London, England); 2020; 395:497-506. PMID: $31986264 \quad$ PPMCID: PMC7159299 DOI: 10.1016/S0140-6736(20)30183-5

5. WHO (World Health Organization). Transmission of SARS-CoV-2: Implications for Infection Prevention Precautions. 2020; Dated 9 July 2020. Retrieved on 20.10 .20 from https://www.who.int/newsroom/commentaries/detail/transmission-of-sarscov-2-implications-for-infection-preventionprecautions

6. Wang D, Hu B, Hu C, Zhu F, Liu X, Zhang J. Clinical Characteristics of 138 Hospitalized Patients with 2019 Novel Coronavirus-infected Pneumonia in Wuhan, China. JAMA. 2020. PMID: $32031570 \quad$ PMCID: PMC7042881 DOI: $10.1001 /$ jama.2020.1585

7. Caruso K. Suicide Causes. 2020. Retrieved on 20.10.20 from http://www.suicide.org/suicidecauses.html.

8. Qiu J, Shen B, Zhao M, Wang Z, Xie B, Xu Y. A Nationwide Survey of Psychological Distress among Chinese People in the Covid-19 Epidemic: Implications and Policy Recommendations. BMJ Journals: General Psychiatry. 2020. https://doi.org/10.1136/gpsych-2020-100213.
9. United Nations. Policy Brief: Covid-19 and People on the Move. (June, 2020). Retrieved https://www.un.org/sites/un2.un.org/files/sg_polic y_brief_on_people_on_the_move.pdf

10. McKibbin WJ, Fernando R. The Global Macroeconomic Impacts of COVID-19: Seven Scenarios (March 2, 2020). CAMA Working Paper No. 19/2020, Available at SSRN: https://ssrn.com/abstract=3547729 or http://dx.doi. org/10.2139/ssrn.3547729

11. Reger MA, Stanley IH, Joiner TE. Suicide Mortality and Coronavirus Disease 2019-A Perfect Storm? JAMA Psychiatry. Published online April 10, 2020. doi:10.1001/jamapsychiatry.2020.1060.

12. Cheng C. Covid-19 in Malaysia: Economic Impacts \& Fiscal Responses, Institute of Strategic and International Studies (ISIS), Malaysia. ISIS Policy Brief: Economic Trade and Regional Integration, 2020; 1-20.

13. Kawohl W, Nordt C. Covid-19, Unemployment, and Suicide. Lancet Psychiatry. 2020; 7(5):389390. doi:10.1016/S2215-0366(20)30141-+

14. Van Orden KA, Witte TK, Cukrowicz KC, Braithwaite SR, Selby EA, Joiner TE Jr. The Interpersonal Theory of Suicide. Psychological Review. 2010; 117(2):575-600. doi: $10.1037 / \mathrm{a} 0018697$

15. Vander Weele TJ, Li S, Tsai AC, Kawachi I. Association between Religious Service Attendance and Lower Suicide Rates among US Women. JAMA Psychiatry. 2016; 73(8):845-851. doi:10.1001/jamapsychiatry.2016.1243.

16. Stanley B, Brown G. Safety Planning Intervention: a Brief Intervention to Mitigate Suicide Risk. Cognitive and Behavioral Practice. May, 2012; 19(2), 256-64.

17. Chan S, Chiu F, Lam C, Leung P, Conwell Y. Elderly Suicide and the 2003 SARS Epidemic in Hong Kong. International Journal of Geriatric Psychiatry. 2006; 21(2):113-18.

18. Bao Y, Sun Y, Meng S, Shi J, Lu L. 2019-nCoV Epidemic: Address Mental Health Care to Empower Society. Lancet (London, England). 2020; 22:395(10224):e37-e38. doi: 10.1016/S0140-6736(20)30309-3.

19. Brooks SK, Webster RK, Smith LE, Woodland L, Wessely S, Greenberg N. The Psychological Impact of Quarantine and How to Reduce it: Rapid Review of the Evidence. Lancet (London, England), 2020. doi:10.1016/S01406736(20)30309-3. Epub 2020 Feb 7.

20. Xiang YT, Yang Y, Li W, Zhang L, Zhang Q, Cheung T. Timely Mental Health Care for the 2019 Novel Coronavirus Outbreak is Urgently Needed. Lancet Psychiatry. In press. 2020. https://doi.org/10.1016/S22159366(20)30046-8

21. Lai J, Ma S, Wang Y. Factors Associated with Mental Health Outcomes Among Health Care 
Workers Exposed to Coronavirus Disease 2019. JAMA Netw Open. 2020; 3(3):e203976. doi:10.1001/jamanetworkopen.2020.3976.

22. Dutheil F, Aubert C, Pereira B. Suicide among Physicians and Health-Care Workers. PLoS One. 2019; 14(12):e0226361. doi:10.1371/journal.pone.0226361

23. WHO (World Health Organization). Suicide Prevention. 2020. Retrieved on 20.10.20 from https://www.who.int/healthtopics/suicide\#tab=tab_1

24. Li W, Yang Y, Liu ZH, Zhao YJ, Zhang Q, Zhang L, Cheung T, Xiang YT. Progression of Mental Health Services during the Covid-19 Outbreak in China. International journal of biological sciences, 2020; 16(10):1732-1738. https://doi.org/10.7150/ijbs.45120)

25. MHIN (The Mental Health Innovation Network). Staff Support during COVID-19: MHPSS Initiatives from Miri General Hospital, Malaysia. Posted $6^{\text {th }}$ May 2020. Retrieved on 20.10.20 from https://www.mhinnovation.net/blog/2020/may/6/st aff-support-during-Covid-19-mhpss-initiativesmiri-general-hospital-malaysia

26. Ping N, Shoesmith, WD, James S, Nor Hadi NM, Yau E, Lin LJ. Ultra Brief Psychological Interventions for Covid-19 Pandemic: Introduction of a Locally-Adapted Brief Intervention for Mental Health and Psychosocial Support Service. The Malaysian journal of medical sciences: MJMS, 2020; 27(2):51-56 https://doi.org/10.21315/mjms2020.27.2.6.

27. Smith M, Segal J, Robinson L. Help Guide Suicide Prevention. 2020. Retrieved from https://www.helpguide.org/articles/suicideprevention/suicide-prevention.htm.

28. Liu S, Yang L, Zhang C, Yu-Tao X, Liu Z, Hu S, Zhang B. Online Mental Health Services in China during the Covid-19 Outbreak. The Lancet Psychiatry. 2020; 7. 10.1016/S22150366(20)30077-8.

29. Figueroa CA, Aguilera A. The Need for a Mental Health Technology Revolution in the Covid-19 Pandemic. Front Psychiatry. 2020; 11:523. doi: 10.3389/fpsyt.2020.00523

30. Garfin DR, Silver RC, Holman EA. The Novel Coronavirus (Covid-19) Outbreak: Amplification of Public Health Consequences by Media Exposure. Health Psychol; 2020; 39(5):355-357. doi: $10.1037 /$ hea0000875.

31. Dolgin R. The Impact of Covid-19 on Suicide Rates. 2020. Updated 13 August, 2020. Retrieved on 20.10.20 from https://www.psycom.net/Covid19-suicide-rates/ 